\title{
Reinforcer value may change within experimental sessions
}

\author{
FRANCES K. MCSWEENEY, JEFFREY N. WEATHERLY, and SAMANTHA SWINDELL \\ Washington State University, Pullman, Washington
}

\begin{abstract}
Large and systematic changes in response rates often occur within sessions during operant conditioning procedures. In the present experiment, we asked whether the value of the reinforcer that supports responding also changes within sessions. Pigeons pecked a key for mixed grain available throughout the session. Occasionally, wheat was also provided for pecking a second key. The ratio of the rates of responding for mixed grain and wheat, a frequently used measure of relative reinforcer value, changed significantly within sessions when mixed grain was provided at high, but not at low, rates. Habituation to the reinforcer provides the most likely explanation for these changes in reinforcer value. Eventually, habituation may provide a unified explanation for the within-session changes in behavior that occur when many species of subjects respond on a wide variety of tasks.
\end{abstract}

Large and systematic changes in response rates occur within sessions when subjects respond on operant conditioning procedures (see, e.g., McSweeney, 1992). Although these changes have been recognized for many years, they have been treated as problems to be controlled by giving warm-up trials (e.g., Hodos \& Bonbright, 1972) or time to adapt to the apparatus (e.g., Papini \& Overmier, 1985), rather than as phenomena to be studied. However, further consideration suggests that within-session changes deserve study in their own right. These changes may be large and reliable (e.g., McSweeney \& Hinson, 1992). They occur for many species of subjects performing a variety of responses on many different procedures (McSweeney \& Roll, 1993). They may also have a number of methodological and theoretical implications (McSweeney \& Roll, 1993). For example, within-session changes challenge both molar (e.g., Herrnstein, 1970) and molecular (e.g., Hinson \& Staddon, 1983) theories. Molar theories are challenged because within-session changes imply that the primary variable used by these theories, rate of responding averaged over the session, masks regularities in behavior at a more molecular level. Molecular theories are challenged because these theories must account for withinsession changes if they are to reach their goal of describing behavior on a moment-by-moment basis.

In the present experiment, we asked whether changes in the effectiveness or the value of the reinforcer produce the within-session changes in response rates. Several authors have argued that the relative value of two reinforcers is indicated by the ratio of the rates of respond-

F.K.M., J.N.W., and S.S. thank Cari B. Cannon for her comments on an earlier version of this manuscript. This material is based on work supported by the NSF (IBN-9403719). The treatment of the subjects was in accordance with institutional guidelines. Correspondence should be addressed to F. K. McSweeney, Department of Psychology, Washington State University, Pullman, WA 99164-4820 (e-mail: fkmcs@mail.wsu.edu). ing for those reinforcers during concurrent schedules (e.g., Baum, 1974). Miller (1976) provided support for this measure. He studied pigeons responding on concurrent variable interval (VI) schedules for hemp versus buckwheat in one condition and for wheat versus buckwheat in a second condition. He found that measures of the value of these three grains that were based on the ratios of the subjects' rates of responding for them could be used to predict the ratio of the rates of responding when subjects responded for hemp versus wheat. Miller argued that such results are compatible with the idea that the ratio of the rates of responding for two reinforcers represents their relative positions on a common scale of reinforcer value.

We used this reasoning in the present experiment. We assumed that if the value of a reinforcer changes within sessions, the ratio of the rate of responding for that "test" reinforcer to the rate of responding for another, "comparison," reinforcer would change within sessions. However, we used a probe procedure instead of a standard concurrent schedule. During a concurrent schedule, the comparison reinforcer is available throughout the session. Therefore, changes in the ratio of the rates of responding for the test and comparison reinforcers may be produced by changes in the value of the comparison, the test, or both reinforcers. Changes in ratios cannot be attributed unambiguously to changes in the value of the test reinforcer alone. Presenting the comparison reinforcer only occasionally for short periods of time (probe procedure) avoids this problem. The value of the comparison reinforcer should not change if subjects are exposed only briefly to this reinforcer. The assumption that the same processes govern responding during probe procedures and during standard schedules is frequently made in the operant literature (e.g., Williams \& Royalty, 1989).

In the present experiment, the test reinforcer was presented at different rates during different conditions. It was assumed that if the value of the reinforcer changed 
with each presentation, larger changes in reinforcer value would be observed when reinforcers were presented more frequently than when they were presented less frequently.

\section{METHOD}

\section{Subjects}

The subjects were 4 experimentally experienced pigeons maintained at approximately $85 \%$ of their free-feeding weights by postsession feedings delivered when all subjects had completed their daily experimental sessions. Subjects were housed individually and were maintained on a 12:12 h light:dark cycle.

\section{Apparatus}

The apparatus was a three-key experimental enclosure, measuring $32.5 \times 30.5 \times 35.5 \mathrm{~cm}$. Three $2.5 \mathrm{-cm}$ diameter response keys appeared $23.5 \mathrm{~cm}$ above the floor and $7.5 \mathrm{~cm}$ apart. The left and right keys were located $6.5 \mathrm{~cm}$ from the left and right walls, respectively. A force of approximately $0.25 \mathrm{~N}$ was required to operate each key. Two $6.5 \times 4 \mathrm{~cm}$ openings allowed access to food magazines. They were located $9.5 \mathrm{~cm}$ below the left and right keys. The experimental panel was housed in a sound-attenuating chamber. A ventilating fan masked noises from outside. Experimental events were programmed and data were recorded by MED-Associates software run on an IBM-compatible computer.

\section{Procedure}

The pigeons had pecked keys in previous experiments. Therefore, they were placed directly on the experimental procedure. During the first condition, pecking the left key that was illuminated with white light produced 5-sec access to mixed grain. Mixed grain was delivered by the left magazine according to a VI 60 -sec schedule. Every $30 \mathrm{sec}$, the right key was illuminated with white light with a probability of .10. When illuminated, the right key remained on for $30 \mathrm{sec}$ and pecking this key yielded 5 -sec access to wheat delivered by the right magazine according to a VI 60 -sec schedule. All reinforcers were scheduled according to a 25-interval Fleshler and Hoffman (1962) series. The series that scheduled mixed grain was independent of the series that scheduled wheat. The timer that scheduled the availability of wheat advanced only when the right key was illuminated. Sessions were $60 \mathrm{~min}$ long, excluding reinforcer time. The houselight was illuminated throughout the session.

The first condition was presented for 30 sessions. When it concluded, the schedule that provided mixed grain was changed. The following schedules were presented in the following order: VI 30-, VI 240-, VI 120-, and VI 15-sec. Each schedule was presented for 30 sessions. All other procedural details were similar to those during the first condition. In particular, wheat was always presented according to a VI 60-sec schedule.

\section{RESULTS}

Figure 1 presents the rates of responding (responses per minute) for mixed grain (top graph) and wheat (middle graph), as well as the ratio of those rates of responding (bottom graph), during successive 5-min intervals in the experimental session. Rate of responding for mixed grain was calculated by dividing the number of responses on the left key during a 5 -min interval by $5 \mathrm{~min}$. Rate of responding for wheat was calculated by dividing the number of responses on the right key during a 5-min interval by the time for which the right key was illuminated during that 5-min interval. The time for which reinforcement was presented was excluded from all calculations of response rates. Ratios were calculated by dividing responding for mixed grain by responding for wheat. Each function presents the results for the mean of
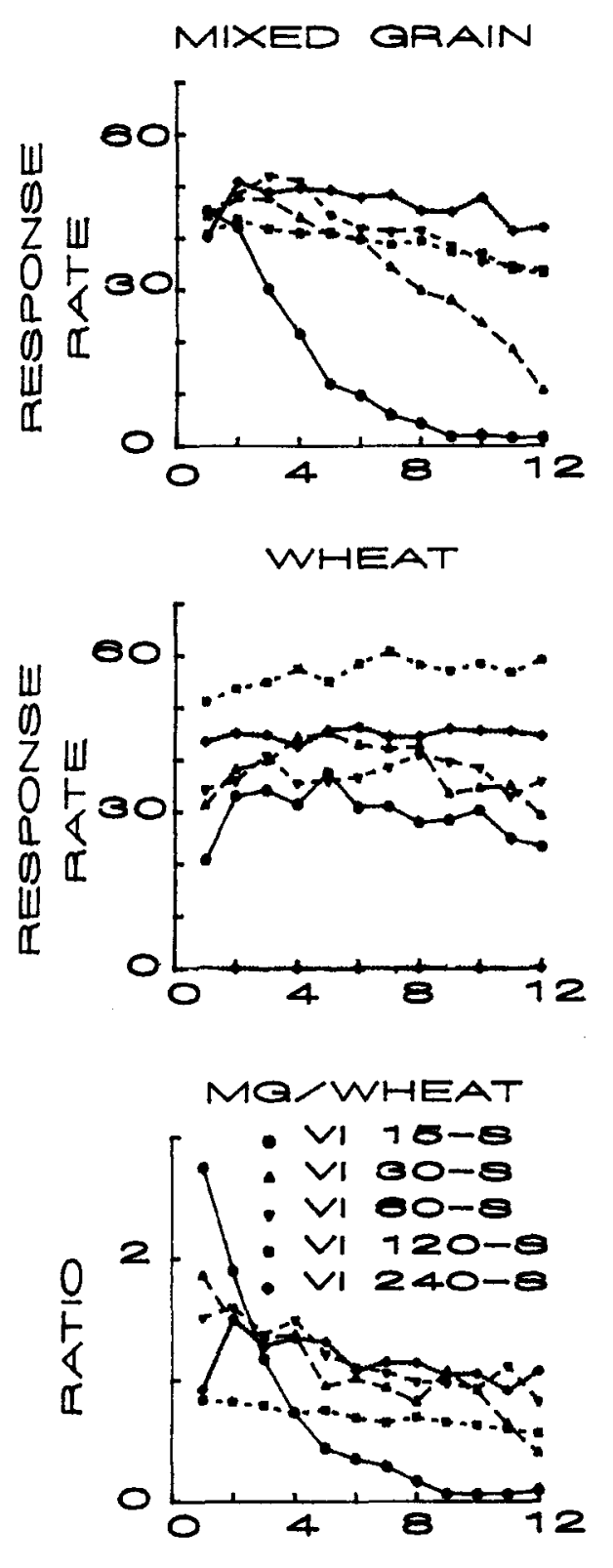

E-MIN INTERVAL

Figure 1. Rates of responding (responses per minute) for mixed grain (top graph), and wheat (middle graph), and the ratios of these rates of responding (bottom graph) during successive 5 -min intervals during the session. Each function presents the results for a different schedule of reinforcement for mixed grain. Results have been averaged over all subjects responding during the last five sessions for which each schedule was available.

all subjects responding on a different schedule of mixedgrain reinforcement. Here, and throughout this paper, results have been averaged over the last five sessions for which a mixed-grain schedule was presented.

Figure 1 (top graph) shows that the rate of responding for mixed grain changed within the session. In particular, responding decreased steeply within sessions when subjects responded for high rates of reinforcement (VI 15and VI 30-sec schedules). It decreased less steeply and 
sometimes increased early in the session when subjects responded for lower rates (VI 60-, VI 120-, and VI 240sec schedules).

Figure 1 (middle graph) shows that responding for wheat remained relatively constant within sessions regardless of the schedule used to present mixed grain. As a result, the ratio of the rates of responding for mixed grain and wheat (bottom graph) changed within sessions in a manner similar to the changes in the rate of responding for mixed grain. That is, the ratio decreased steeply within the session during the VI 15- and VI 30$\mathrm{sec}$ schedules. It decreased less steeply and sometimes increased early in the session during the VI 60-, VI 120-, and VI $240-$ sec schedules.

Table 1 confirms these conclusions. It presents the results of one-way (5-min interval) analyses of variance (ANOVAs) applied to the rates of responding for mixed grain and wheat, and to the ratios of those response rates. Some polynomial contrasts are also presented. A significant linear contrast means that responding decreased within sessions. A significant quadratic contrast indicates that responding increased and then decreased.

Table 1 shows that responding for wheat did not change significantly within sessions in any condition. Responding for mixed grain changed significantly for the VI 15-, VI 30-, and VI 60-sec schedules. At least one polynomial contrast was also significant for each of these schedules, indicating that responding changed sys-

Table 1

Results of One-Way (5-Min Interval) Analyses of Variance (ANOVAs) Applied to the Rates of Responding for Mixed Grain and Wheat and to Their Ratios for Each Schedule of Mixed Grain Reinforcement

\begin{tabular}{|c|c|c|c|c|c|}
\hline \multirow{2}{*}{$\begin{array}{l}\text { VI Schedule } \\
\text { (in Seconds) }\end{array}$} & \multicolumn{2}{|c|}{ ANOVA } & \multicolumn{3}{|c|}{ Polynomial Contrast } \\
\hline & $F$ & $p$ & Type & $F$ & $p$ \\
\hline \multicolumn{6}{|c|}{ Mixed Grain } \\
\hline 15 & 40.509 & .001 & $\begin{array}{l}\text { linear } \\
\text { quadratic }\end{array}$ & $\begin{array}{l}75.383 \\
29.145\end{array}$ & $\begin{array}{l}.003 \\
.012\end{array}$ \\
\hline 30 & 11.995 & .001 & linear & 31.032 & .011 \\
\hline 60 & 8.324 & .001 & $\begin{array}{l}\text { linear } \\
\text { quadratic }\end{array}$ & $\begin{array}{l}13.808 \\
19.723\end{array}$ & $\begin{array}{l}.034 \\
.021\end{array}$ \\
\hline $\begin{array}{l}120 \\
240\end{array}$ & $\begin{array}{l}2.045 \\
2.026\end{array}$ & $\begin{array}{l}.056 \\
.058\end{array}$ & linear & 14.871 & .031 \\
\hline \multicolumn{6}{|c|}{ Wheat } \\
\hline $\begin{array}{r}15 \\
30 \\
60 \\
120 \\
240\end{array}$ & $\begin{array}{l}1.285 \\
1.851 \\
0.461 \\
0.748 \\
0.084\end{array}$ & $\begin{array}{r}.276 \\
.085 \\
.914 \\
.686 \\
1.000\end{array}$ & & & \\
\hline \multicolumn{6}{|c|}{ Ratio (Mixed Grain/Wheat) } \\
\hline 15 & 7.300 & .001 & linear & 9.823 & .052 \\
\hline 30 & 3.565 & .002 & linear & 7.675 & \\
\hline 60 & 1.764 & .102 & & & \\
\hline 120 & 2.063 & .053 & & & \\
\hline 240 & 0.920 & .533 & & & \\
\hline
\end{tabular}

Note-Significant $(p<.05)$ and nearly significant $(p<.10)$ linear and quadratic polynomial contrasts are also presented. The degrees of freedom were 11,33 for response rates and ratios, and 1,3 for polynomial contrasts. VI, variable interval. tematically within the session during these conditions. The ratio of the rates of responding for mixed grain and wheat also changed significantly within sessions for the VI 15- and VI 30-sec schedules.

\section{DISCUSSION}

Rate of responding for mixed grain, and the ratio of the rates of responding for mixed grain and wheat, changed significantly within sessions when mixed grain was provided at high, but not at low, rates. Because the ratio of the rates of responding for two reinforcers is sometimes taken as an index of their relative values (e.g., Miller, 1976), the present results suggest that the value of mixed grain relative to wheat sometimes changed within experimental sessions. These changes in relative value can be attributed to changes in value of mixed grain, rather than to changes in the value of wheat, because the rate of responding for wheat did not change within the session during any condition.

Satiation for the reinforcer and habituation to the reinforcer provide two potential explanations for the within-session changes in reinforcer value. These explanations are consistent with two aspects of the present data. First, both satiation (Rolls, Rolls, Rowe, \& Sweeney, 1981) and habituation (Swithers \& Hall, 1994) can be specific to the stimulus presented. Therefore, these processes might produce different within-session changes for the two reinforcers, as observed in Figure 1. Second, more satiation should occur when more food is consumed and more habituation should occur when more stimuli are presented. Therefore, larger changes in the value of mixed grain should be observed when mixed grain was provided at higher, rather than at lower, rates, as observed in Figure 1. To clarify the difference between sensitization-habituation to a reinforcer and satiation for that reinforcer, sensitization-habituation usually refers to an increase followed by a decrease in responding to a repeatedly presented stimulus. Satiation usually refers to the decline in consumption of an ingestive stimulus such as food or water. Sensitization-habituation to sensory aspects of the ingestive stimulus may contribute to satiation for that stimulus, but other factors, such as gastric fill, nutritional state, postingestive factors, and so on, also contribute to satiation (Swithers \& Hall, 1994).

McSweeney, Hinson, and Cannon (in press) argued that sensitizationhabituation to aspects of the experimental procedure that are presented repeatedly (e.g., reinforcers) or for a prolonged time (e.g., the experimental chamber) provides a better explanation than satiation for the within-session changes in operant responding. First, McSweeney et al. showed that the empirical characteristics of within-session patterns of operant responding are similar to the empirical characteristics of behavior reported in the literature on sensitization-habituation. Second, they argued that sensitization-habituation, but not satiation, can account for within-session changes in responding that are sometimes reported when no reinforcers are given (see, e.g., Schoenfeld, Antonitis, \& Bersh, 1950). Finally, they showed that several factors that influence the consumption of ingestive stimuli (i.e., factors that alter satiation) have little or no effect on within-session patterns of operant responding. For example, Roll, McSweeney, Johnson, and Weatherly (1995) varied the caloric density of the reinforcers, the size of the reinforcers, and the subjects' deprivation for the reinforcers by feeding them before the session or by changing their maintenance body weights. Prefeeding the subjects, varying their maintenance body weights, and varying the caloric density of the reinforcers had no effect on the within-session patterns of responding. Varying reinforcer size altered within-session patterns, but only when the size of the reinforcer increased by a factor of 5 , not by a factor of 3 . In each experiment, rate of responding averaged over the session changed appropriately with the experimental manipulation. For example, the average rate of responding was faster when subjects responded at $75 \%$ than at $85 \%$ or $95 \%$ of their free-feeding weights. Therefore, it is unlikely that the experimental manipulations failed to alter the subjects' level of satiation (see also Cannon \& McSweeney, 1995; McSweeney \& Johnson, 1994; Weatherly, McSweeney, \& Swindell, 1995).

Figure 1 may provide additional support for sensitization-habituation as an explanation for within-session changes in operant responding. McSweeney et al. (in press) argued that this explanation could be tested 
by looking for two empirical characteristics of sensitization-habituation that have not yet been shown for operant responding. First, responding to a habituated stimulus is often restored after a novel stimulus is presented (dishabituation). Second, habituation is relatively specific to the stimulus that has been presented (stimulus specificity). Figure 1 provides preliminary evidence for the stimulus specificity of withinsession changes in operant responding because different within-session changes occurred for the two different reinforcers.

If the present results show that subjects habituate to repeatedly presented reinforcers, they have a number of implications. To begin with, little is known about habituation during steady-state procedures. Studying within-session changes in operant responding may provide information on this topic. More importantly, habituation is not restricted to operant situations. Therefore, habituation may eventually provide a unified explanation for the similar within-session changes in behavior that occur over time on task in a wide variety of situations. These situations include responses that are evoked by stimuli (habituation; e.g., Thompson \& Spencer, 1966); classically conditioned responding (e.g., Lubow, 1965); consummatory responding (e.g., Rachlin \& Krasnoff, 1983); "spontaneously" occurring behaviors (e.g., activity, locomotion, and exploration; Montgomery, 1953); and leverpressing before conditioning begins (e.g., Schoenfeld et al., 1950). Because some similar changes in human performance (e.g., declines in vigilance) have already been attributed to habituation (e.g., Mackworth, 1968), habituation may eventually provide a bridge between the literatures on within-session changes in responding in human and nonhuman subjects.

\section{REFERENCES}

BaUM, W. M. (1974). On two types of deviation from the matching law: Bias and undermatching. Journal of the Experimental Analysis of Behavior, 22, 231-242.

CANNON, C. B., \& MCSWEENEY, F. K. (1995). Within-session changes in responding when rate and duration of reinforcement vary. $B e$ havioural Processes, 34, 285-292.

FleshleR, M., \& HofFMAN, H. S. (1962). A progression for generating variable-interval schedules. Journal of the Experimental Analysis of Behavior, 5, 529-530.

HerRnstein, R. J. (1970). On the law of effect. Journal of the Experimental Analysis of Behavior, 13, 243-266.

Hinson, J. M., \& STADDON, J. E. R. (1983). Hill-climbing by pigeons. Journal of the Experimental Analysis of Behavior, 39, 25-47.

Hodos, W., \& Bonbright, J. C., JR. (1972). The detection of visual intensity differences by pigeons. Journal of the Experimental Analysis of Behavior, 18, 471-479.

LUBow, R. E. (1965). Latent inhibition: Effects of frequency of nonreinforced preexposure of the CS. Journal of Comparative \& Physiological Psychology, 60, 454-457.
Mackworth, J. F. (1968). Vigilance, arousal and habituation. Psychological Review, 75, 308-322.

MCSWEENEY, F. K. (1992). Rate of reinforcement and session duration as determinants of within-session patterns of responding. Animal Learning \& Behavior, 20, 160-169.

MCSWEENEY, F. K., \& Hinson, J. M. (1992). Patterns of responding within sessions. Journal of the Experimental Analysis of Behavior, 58, 19-36.

McSweeney, F. K., Hinson, J. M., \& Cannon, C. B. (in press). Sensitization-habituation may occur during operant conditioning. Psychological Bulletin.

MCSWeeney, F. K., \& Johnson, K. S. (1994). The effect of time between sessions on within-session patterns of responding. Behavioural Processes, 31, 207-218.

MCSWeEney, F. K., \& Roll, J. M. (1993). Responding changes systematically within sessions during conditioning procedures. Journal of the Experimental Analysis of Behavior, 60, 621-640.

Miller, H. L., JR. (1976). Matching-based hedonic scaling in the pigeon. Journal of the Experimental Analysis of Behavior, 26, 335347.

MONTGOMERY, K. C. (1953). The effect of activity deprivation upon exploratory behavior. Journal of Comparative \& Physiological Psychology, 46, 438-441.

PaPINI, M. R., \& OVermier, J. B. (1985). Partial reinforcement and autoshaping of the pigeon's key-peck behavior. Learning \& Motivation, 16, 109-123.

Rachlin, H., \& Krasnoff, J. (1983). Eating and drinking: An economic analysis. Journal of the Experimental Analysis of Behavior, 39, 385-404.

ROLL, J. M., MCSWEENEY, F. K., JOHNSON, K. S., \& WEATHERLY, J. N (1995). Satiety contributes little to within-session decreases in responding. Learning \& Motivation, 26, 323-341.

Rolls, B. J., Rolls, E. T., Rowe, E. A., \& SWeeney, K. (1981). Sensory specific satiety in man. Physiology \& Behavior, 27, 137-142.

Schoenfeld, W. N., Antonitis, J. J., \& Bersh, P. J. (1950). Unconditioned response rate of the white rat in a barpressing apparatus. Journal of Comparative \& Physiological Psychology, 43, 41-48.

Swithers, S. E., \& Hall, W. G. (1994). Does oral experience terminate ingestion? Appetite, 23, 113-138.

ThOMPSON, R. F., \& SPENCER, W. A. (1966). Habituation: A model phenomenon for the study of neuronal substrates of behavior. Psychological Review, 73, 16-43.

WeATHERLY, J. N., MCSWEeney, F. K., \& SWindell, S. (1995). On the contributions of responding and reinforcement to within-session patterns of responding. Learning \& Motivation, 26, 421-432.

Williams, B. A., \& Royalty, P. (1989). A test of the melioration theory of matching. Journal of Experimental Psychology: Animal Behavior Processes, 15, 99-113. 